\title{
Paracetamol Overdose Induces Physiological and Pathological Aberrations in Rat Brain
}

\author{
Amina E. Essawy ${ }^{1}$, Afrah F. Alkhuriji ${ }^{2}$, Ahmed A. Soffar ${ }^{1}$ * \\ ${ }^{1}$ Department of Zoology, Faculty of Science, Alexandria University, Alexandria, Egypt. \\ ${ }^{2}$ Department of Zoology, College of Science, King Saud University, Saudi Arabia.
}

\begin{tabular}{|c|c|}
\hline ARTICLE INFO & ABSTRACT \\
\hline $\begin{array}{l}\text { Article history: } \\
\text { Received on: } 15 / 04 / 2017 \\
\text { Accepted on: } 26 / 06 / 2017 \\
\text { Available online: } 30 / 09 / 2017\end{array}$ & $\begin{array}{l}\text { Paracetamol (Acetaminophen) is one of the most popular over the counter medications that is commonly used as } \\
\text { an anti-inflammatory and pain killer, and to relieve fever and headaches. Despite its several therapeutic benefits, } \\
\text { it is well known that an overdose of paracetamol can lead to hepatic and renal damage. Considering that brain } \\
\text { cells is one of the main targets for paracetamol in the body, the effect of paracetamol on the physiology and }\end{array}$ \\
\hline $\begin{array}{l}\text { Key words: } \\
\text { Paracetamol, neurotoxicity, } \\
\text { neurochemicals, } \\
\text { histopathology. }\end{array}$ & $\begin{array}{l}\text { effects of paracetamol on the rat brain. Our results show that an overdose treatment of paracetamol caused } \\
\text { significant elevation in the activity of AChE and a remarkable suppression in levels of dopamine and serotonin } \\
\text { in treated rats. Also, applying rapid Golgi-cox staining showed that paracetamol induced morphological } \\
\text { aberrations and a dramatic reduction in the density of dendritic spines in brain cells. Histological and } \\
\text { ultrastructure alterations were also recorded in the neurons of paracetamol-treated rats. In conclusion, we found } \\
\text { that an overdose of paracetamol is neurotoxic. The observed alterations point to the possibilities of higher brain } \\
\text { impairments which is of strong public health concern. }\end{array}$ \\
\hline
\end{tabular}

\section{INTRODUCTION}

Paracetamol

(Acetaminophen,

N-Acetyl-pAminophenol) is widely used as prescription and over the counter (OTC) analgesic and antipyretic agent (Trumper et al., 2005). A major problem is the misuse of paracetamol through intentional or unintentional uptake of supratherapeutic doses, which may lead to hepatic and renal adverse side effects in humans and experimental animals (Guo and Nzerue 2002; Toklu et al., 2006). Paracetamol is metabolized mainly in the liver via conjugation with glucuronic acid and sulphate, and finally excreted in urine. Paracetamol metabolism also yields a cytochrome P450-dependent highly reactive metabolite known as

\footnotetext{
* Corresponding Author

Ahmed Soffar, Department of Zoology, Faculty of Science, Alexandria University, Alexandria, Egypt.Email: ahmedsoffar @ gmail.com
}

$\mathrm{N}$-acetyl-p-benzoquinonimine (NAPQI). This metabolite is able to react with glutathione (GSH) forming a non-toxic conjugate to be excreted via kidneys (Henderson et al., 2000; Manyike et al., 2000; Walubo et al., 2004). Critically, overdoses of paracetamol saturates these neutralization metabolic pathways thus the rate of formation of NAPQI exceeds the capacity to detoxification. The excess NAPQI binds to cellular proteins, including mitochondrial proteins, leading to an oxidative stress-mediated liver damage (Henderson et al., 2000; Ojo et al., 2006). Importantly, Cytochrome P450 isoform CYP2E1 is also expressed in the brain, suggesting that paracetamol might be metabolized by nerve cells producing the toxic metabolite NAPQI (Joshi and Tyndale 2006). Also, considering its feasibility to crosses the blood brain barrier, a high dose of paracetamol may lead to NAPQI-mediated adverse neurotoxic effects (Fischer et al., 1981). Despite intensive investigations of the toxic effect on liver and kidney tissues, information about pathological effects of paracetamol on the neuronal tissue is relatively rare. 
Hence, the purpose of this work is to clarify the effect of paracetamol overdose on nerve tissues. We investigated the effect of paracetamol on the physiological activity of Acetylcholinesterase (AChE) and monoamines (dopamine and serotonin). Importantly, we coupled our physiological study with an intensive investigation for the anatomical as well as the cellular and subcellular changes in the brain tissue in response to paracetamol treatment.

\section{MATERIALS AND METHODS}

\section{Experimental animals}

A total of 16 adult male Wistar albino rats, of 150-160 g body weight, were used in this study. Animals were housed in standard metallic cages (4 rats per cage) and kept in a temperaturecontrolled environment $\left(22 \pm 2{ }^{\circ} \mathrm{C}\right)$ with an alternating $12 \mathrm{~h}$ lightdark cycle. Rats were acclimatized to the lab environment for 1 week prior to the experiment. The animals had free access to commercial food pellets and clean drinking water. The experiments were done in compliance with the Guide for the Care and Use of Laboratory Animals.

\section{Chemicals used}

Paracetamol (Panadol 665, GlaxoSmithKline Australia Pty Limited, Australia) was obtained from a local medical store (Alexandria, Egypt). Kits for the measurement of serum AChE were purchased from Span Diagnostics Ltd. (Surat, India). Dopamine and serotonin ELISA measurement kits were purchased from GenWay Biotech Inc. (San Diego, CA, USA) and DLDGesellschaft für Diagnostika und medizinische Geräte $\mathrm{mbH}$ (Hamburg, Germany) respectively.

\section{Experimental design}

Animals were randomly divided into 2 groups of 8 rats each. Group 1: Animals were orally given distilled water $(2 \mathrm{ml})$ for 15 days and served as controls. Group 2: Animals were orally given paracetamol $(650 \mathrm{mg} / \mathrm{kg}$ b.wt. dissolved in $2 \mathrm{ml}$ distilled water (Yousef et al., 2010)) daily for 15 days. Blood samples were collected from both control and experimental animals as described in (Khayyat et al., 2017), then animals were sacrificed and brains were quickly removed and prepared for neuroanatomical, histological and ultrastructural studies as described below.

\section{Measurement of neurochemicals}

We measured the Acetylcholinesterase activity in the serum of animals. Briefly, serum was separated out from blood samples by centrifugation at $3000 \mathrm{rpm}$ for $10 \mathrm{~min}$. AChE activity was determined in plasma using acetylcholine iodide as a substrate as described in (Ellman et al., 1961). In this method, AChE in samples hydrolyzes acetylthiocholine iodide into thiocholine and butyric acid. The thiocholine reacts with 5,5'-dithiobis-2nitrobenzoic acid to form 5-thio-2-nitrobenzoic acid. The developed yellow color is measured spectrophotometrically. Dopamine and serotonin levels were measured in the brain tissue of control and paracetamol-treated animals according to manufacturer's protocols. All measurements were carried out using Elico-SL177 spectrophotometer (Elico LTD. Hyderabad Andra Pradesh, India).

\section{Neuroanatomical study}

For detection of the morphological changes in perikarya, dendrites and axons, rapid Golgi-cox staining technique was used (Shankaranarayana Rao et al., 2001). Animals from control and paracetamol-treated groups were deeply anesthetized with diethyl either. Brains were carefully removed from skulls and immersed en-block in rapid Golgi solution in colored bottles for 1 day and replaced with fresh fixative. The composition of Golgi solution was: $5 \%$ potassium dichromate, 5\% chloral hydrate, $4 \%$ glutaraldehyde, $2.5 \%$ formaldehyde, $0.5 \%$ DMSO (Adermark and Lovinger 2006). One day later, the fixative in which the tissue was immersed on day 1 was slowly poured out. The tissue was rinsed for 2 days by adding a small amount of fresh fixative and kept in the dark chamber every $24 \mathrm{~h}$. The tissue blocks remained undisturbed in the fixative for another $24 \mathrm{~h}$ and then were rinsed for 4 days in $0.75 \%$ aqueous solution of silver nitrate $\left(\mathrm{AgNO}_{3}\right)$ till the reddish-brown color of the potassium dichromate-silver complex disappeared.

Tissue pieces were placed in a petri dish and silver deposits were gently brushed off. After dehydration, the tissue blocks were carefully mounted onto block holders with required orientation and embedded with paraffin wax. The brain tissue was cut into $100 \mu \mathrm{m}$ thick sections in horizontal plane. The sections were collected in a Petri dish containing $100 \%$ alcohol and transferred to xylene for clearing and finally were mounted serially on slides with DPX. Slides images were captured using an Olympus Fluorescent Microscope imaging system.

\section{Histological and Ultrastructural studies}

For histopathological study, brains of control and paracetamol-treated animals were dissected out and fixed in $10 \%$ formalin for $24 \mathrm{~h}$. Washing was done by rinsing the sample in tap water for $24 \mathrm{~h}$. Sample dehydration was performed using serial dilutions of ethanol. Specimens were cleared in xylene and embedded in paraffin. Paraffin sections $(5 \mu \mathrm{m})$ were stained by hematoxylin and eosin according to (Bancroft et al., 1996) for histopathological examination.

For ultrastructural examination, small pieces of brain were immediately immersed in $4 \mathrm{~F} 1 \mathrm{G}$ in phosphate buffer $(\mathrm{pH} 7.2)$ fixation mixture for $3 \mathrm{~h}$ at $4{ }^{\circ} \mathrm{C}$ then post-fixed in $2 \% \mathrm{OsO}_{4}$ (Osmium tetroxide) at $4{ }^{\circ} \mathrm{C}$ for $2 \mathrm{~h}$. The specimens were dehydrated in graded series of ethanol then embedded in Eponaraldite mixture in labeled beam capsules. LKB ultramicrotome was used to obtain ultrathin sections (50 nm thick) which were picked upon 200 mesh naked copper grids. Grids were double stained with uranyl acetate for $1 / 2 \mathrm{~h}$ and lead citrate for $20-30 \mathrm{~min}$. Scoping the grids was achieved by using Jeol 100CX Transmission electron microscope (TEM). 


\section{Statistical Analysis}

The results were expressed as mean \pm SD were analyzed by Student's $t$-test using Microsoft excel® 2016. Values of $p<$ 0.05 were considered to be statistically significant.

\section{RESULTS}

\section{Paracetamol treatment alters the activity of} Acetylcholinesterase and levels of monoamines

The activity of AChE in plasma of control and paracetamol-treated rats are shown in Figure (1a). Interestingly, we found a significant $(p<0.05) 3$-fold increase in the level of AChE activity in paracetamol-treated rats as compared to control rats $(174.7 \pm 58.8 \& 53 \pm 12.5$ unit/L respectively). On the other hand, levels of the two key player neurotransmitters within the brain tissue, dopamine and serotonin, were suppressed to more or less half their original levels as compared to controls (Figs. 1b, c).

\section{Morphological aberrations of dendrites and dendritic spines after paracetamol treatment}

In this work, we applied Golgi-cox staining to brain section to reveal detailed morphological architecture of neurons. The neuronal cell bodies together with their projections are stained dark brown in the after impregnated by Golgi-cox stain. Brain sections of control rats are represented by figures $2 \mathrm{a}$ and $\mathrm{b}$. In controls, perikarya appear polygonal or oval. Neuronal spines are well recognizable and appeared as membranous protrusions arising from the neuronal surface of dendrites. Brain sections of paracetamol-treated animals show morphological abnormalities including a clear initial degeneration of neuronal axons (Fig. 2c).

Moreover, we observed a dramatic reduction in the density of the dendritic spines in brain sections from animals treated with paracetamol as compared to controls (Fig. 2d).

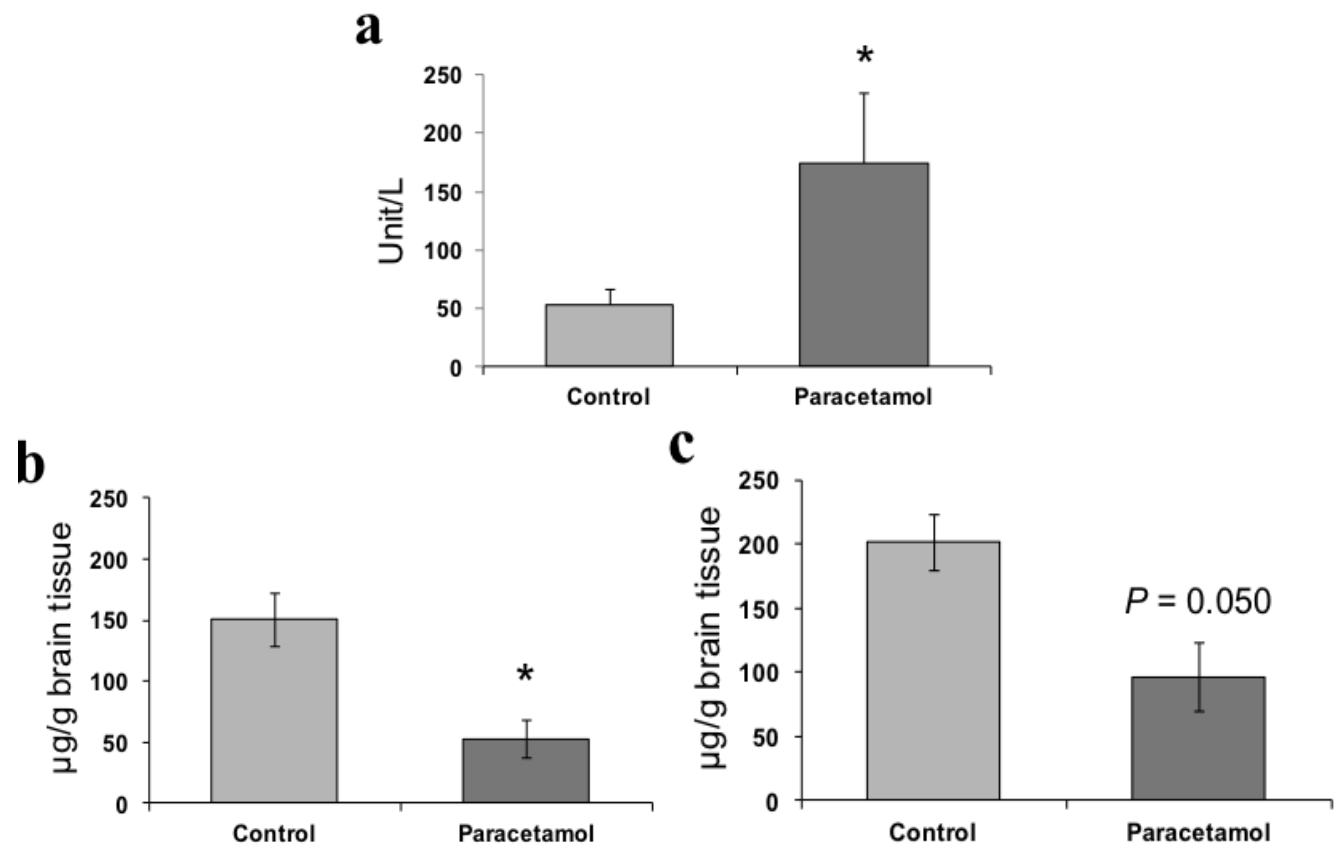

Fig. 1: Neurochemical analysis of AChE activity and dopamine, and serotonin levels after Paracetamol administration. (a) Serum levels of AChE activity in control- and Paracetamol-treated rats. Values are mean \pm SD for three rats in each group. ${ }^{*} \mathrm{p}<0.05$. (b) Brain tissue levels of dopamine in control- and Paracetamol-treated rats. (c) Brain tissue levels of serotonin in control- and Paracetamol-treated rats. Values are mean \pm SD for three rats in each group. *p < 0.05 .
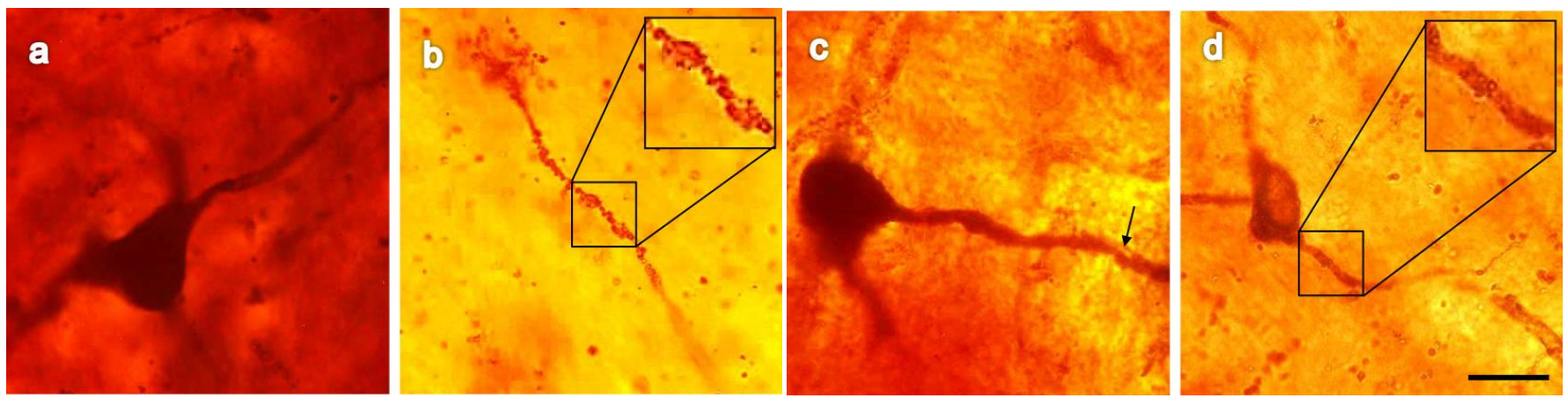

Fig. 2: Light micrographs of cortical neurons from control and Paracetamol-treated rats (Golgi-cox stain). (a) A control neuron from control rat with normal architecture of perikaryon, axon and dendrites. (b) A typical dendron of a neuron of control rat carrying many dendritic spines (enlarged part). (c) A neuron from Paracetamol-treated rat showing degenerated parts a long its axon (arrow). (d) A dendron from Paracetamol-treated rat showing dramatic reduction in spine number as compared with control neurons. (a - d), Scale bar, $10 \mu \mathrm{m}$; enlarged parts, $5 \mu \mathrm{m}$. 


\section{Paracetamol induces histopathological and ultrastructural alterations in brain tissue}

Normal histological architecture of the brain tissue was shown in brain sections from control rats (Fig. 3a). Paracetamol treatment induced several histopathological alterations in both neurons and neuroglia cells of brain tissue. Several neurons showed signs of degeneration, including cytolysis and chromatolysis (Fig. 3b). Spongiform necrosis and nuclear pyknosis were observed (Fig. 3b). Also, we observed degenerated neuroglia containing pyknotic nuclei and congested cerebral blood vessels with detached endothelial wall in paracetamol-treated animals (Fig. 3c). Electron micrographs of brain cortex of untreated rats showed normal neuronal soma and normal neuropile with myelinated and unmyelinated nerve fibers containing normal mitochondria and normal light and electron dense synaptic vesicles (Figs. 4a \& b). Normal protoplasmic glial cells were also seen (Fig. 4a).

Degenerated neurons with complete lyses of cytoplasm, irregularly shaped nuclei, dilated and disorganized cisternae of rough endoplasmic reticulum, damaged mitochondria and ruptured synaptic vesicles were observed in brain of animals treated with paracetamol (Figs. 4c-e). The cytoplasm of some glial cells appeared electron dense, with altered mitochondria and disorganization of the inner membrane system.
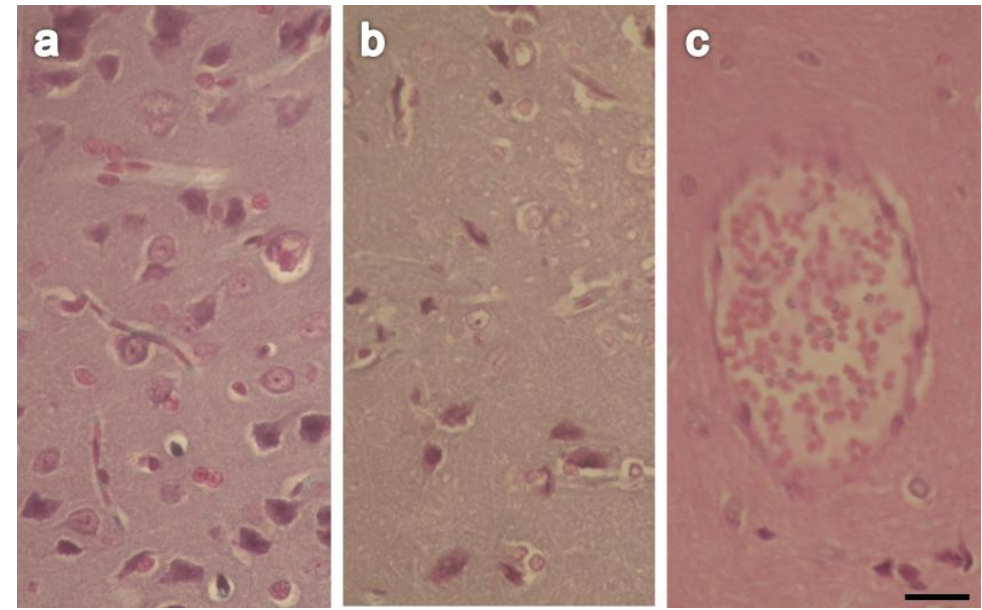

Fig. 3: Light micrographs showing histological changes in the brain of rat after treatment with Paracetamol. (a) A group of cortical neurons of control rat with large globular or ovoid nuclei surrounded by a small amount of cytoplasm. (b) A group of neurons of Paracetamol-treated rat showing signs of degeneration including cytolysis and chromatolysis. (c) Cerebral congested, dilated blood vessel in Paracetamol-treated rat with detached endothelial wall. Scale bar, $20 \mu \mathrm{m}$.
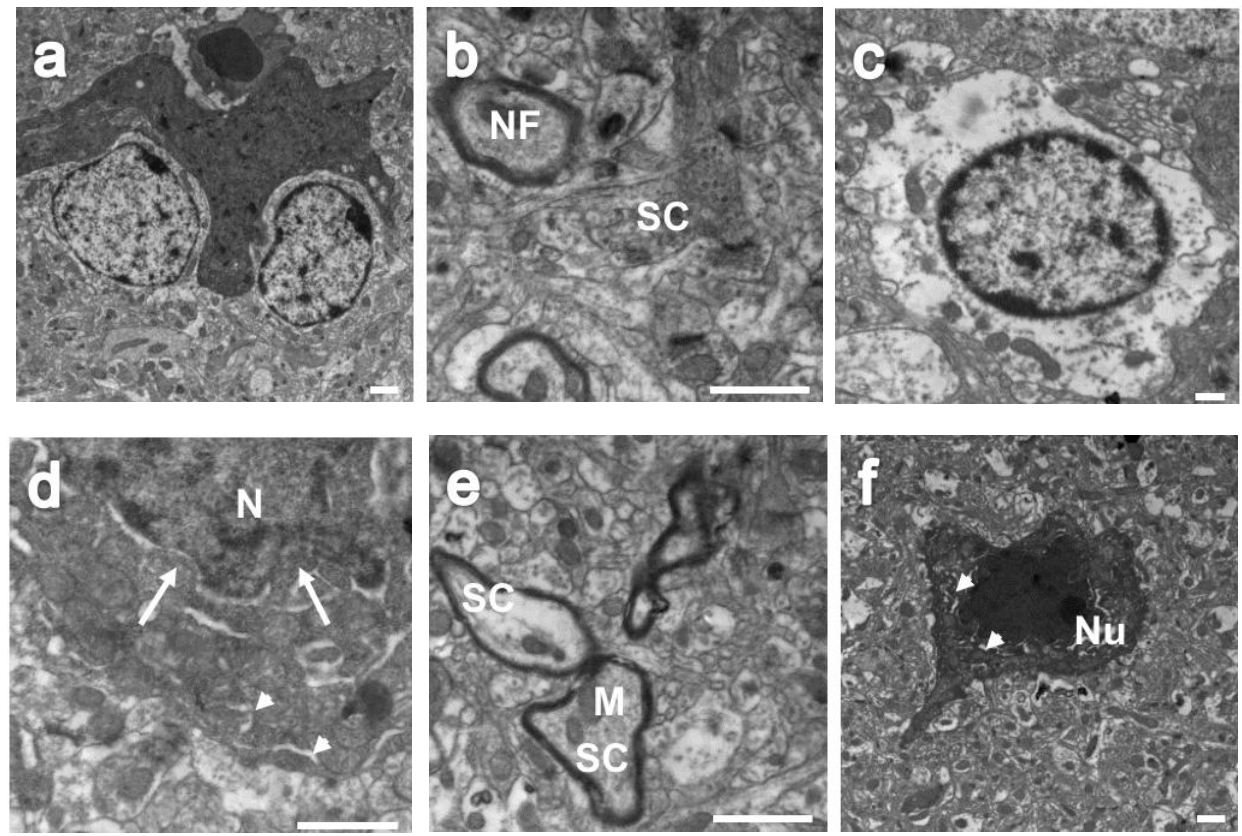

Fig. 4: Electron micrographs showing parts of the cerebral cortex of control (a, b) and Paracetamol-treated rats (c - f). (a) Two neurons and their serving microglia cell (MC). (b) Myelinated nerve fiber (NF) with synaptic vesicles (SV). (c) A neuron with complete lysis of the cytoplasm and damaged cytoplasmic organelle. (d) Enlarged part of a neuron, showing irregular-shaped nucleus (N) with indentation and dilation of the nuclear envelope (arrows). Note also: cytoplasm containing dilated and disorganized cisternae of endoplasmic reticulum (arrowheads). (e) Nerve fibers (NF) containing degenerated synaptic vesicles and damaged mitochondria (M). (f) A glial cell with abnormal outline and electron dense nucleus possessing severe indentation of nuclear envelope and peripherally located nucleolus $(\mathrm{Nu})$. Arrowheads indicate fragments of dilated rough endoplasmic reticulum. Scale bar, $500 \mathrm{~nm}$. 


\section{DISCUSSION}

In this study, we found that application of an overdose of paracetamol significantly elevated the plasma level of AChE in treated animals. It also produced several morphological, histological and ultrastructure aberrations thus indicating a possible brain injury. A recent study reported that an overdose treatment of paracetamol caused a significant increase in malondialdehyde (MDA) that is associated with a remarkable decrease of total antioxidant capacity in the brain of male albino rats (Mohammed and Safwat 2013). Moreover, the elevated level of MDA in the brain following a high paracetamol dose correlates with an increased rate of lipid peroxidation which is one of the main manifestations of oxidative damage (Sener et al., 2003). The elevated AChE activity could be attributed to neuronal membrane damage due to increased lipid peroxidation (Kaizer et al., 2005). Importantly, the increased AChE activity following administration of high doses of paracetamol will positively reduce the cholinergic neurotransmission efficiency by decreasing the level of acetylcholine in the synaptic cleft, but, on the other hand, may lead to an oxidative stress-mediated structural alteration in neurons.

Our study showed also that administration of high doses of paracetamol induced a significant depletion in dopamine and serotonin content in brain tissue. A recent study demonstrated a significant effect of the long term paracetamol treatment on the level of amino acids in different regions of the rat brain (BlecharzKlin et al., 2014). They reported that, the abnormal variability in various amino acids concentrations may be attributed to a wide range of pharmacological effects of paracetamol in the central nervous system. Also, the damage of neurons and the depletion of neurotransmitter level could be attributed to paracetamol-induced oxidative stress. A recent work showed that paracetamol administration caused a significant elevation in levels of thiobarbituric acid reactive substances (TBARS) and dichlorofluorescein oxidation in brain homogenate (da Silva et al., 2012). Also, mitochondrial swelling and reactive oxygen species production increased after administration of paracetamol. Considering their important functions as neurotransmitters, the observed paracetamol-associated reduction in levels of dopamine and serotonin may critically lead to behavioral and emotional adverse side effects.

In the present work, our neuroanatomical study using rapid Golgi-cox staining technique revealed a dramatic reduction in the number of neural spines upon paracetamol treatment. Dendritic spines contain several essential compartments for synaptic function and plasticity such as neurotransmitter receptors, organelles, and signaling systems (Cheng et al., 2010; Nimchinsky et al., 2002). Defect in morphology or alterations in density of neural spines is associated with a growing number of human disorders (Lai et al., 2016). A link between abnormal neural spines and mental retardation was suggested for first time by (Purpura 1974). Also, mental disorders such as schizophrenia is associated with decreased density of dendritic spines in neocortical pyramidal neurons (Garey et al., 1998). In addition, patients with Down syndrome have a decreased spine density in neocortex (Takashima et al., 1989) and hippocampus (Ferrer and Gullotta 1990). On the contrary, a low dose of paracetamol may protect cerebral cortical neurons from oxidative stress and limits neuronal inflammation by reducing menadione-mediated oxidative neurotoxicity (Bisaglia et al., 2002; Tripathy and Grammas 2009).

Our histological and ultrastructure investigation revealed different degenerative changes in brain cells in response to paracetamol treatment. These results coincide with the findings of (Posadas et al., 2010) who reported a deleterious effect of paracetamol on cortical neurons, both in vivo and in vitro. In addition, paracetamol induces neuronal damage in cerebral granular cells (Mohamed et al., 2014). Also, paracetamol is able to activate the neuronal CYP2E1 thus generating toxic metabolites such as NAPQI. The formation of NAPQI metabolite decreases glutathione levels leading to oxidative stress and neurotoxicity (Joshi and Tyndale 2006). Also, (Nencini et al., 2007) reported that, an overdose of paracetamol decreases the levels of antioxidative stress candidates such as glutathione, ascorbic acid and is associated with a remarkable decrease in superoxide dismutase activity. Importantly, excessive production of reactive oxygen species in brain and the disturbance in balance between oxidative species antioxidant defenses are associated to pathological changes in neurodegenerative diseases (Halliwell 2006).

\section{CONCLUSION}

In conclusion, the results of this study point to the fact that administration of an overdose of paracetamol is neurotoxic. The remarkable degenerative changes upon Pacarcetamol administration in brain tissue of rats may be attributed to excessive oxidative stress. Future studies are necessary to clarify the exact neurotoxic mechanism of paracetamol in case of being used at high doses.

\section{Financial support and sponsorship: Nil.}

Conflict of Interests: There are no conflicts of interest.

\section{REFERENCES}

Adermark L, Lovinger DM. Ethanol effects on electrophysiological properties of astrocytes in striatal brain slices. Neuropharmacology. 2006;51(7-8):1099-108.

Bancroft JD, Stevens A, Turner DR. Theory and practice of histological techniques. 4. ed. New York: Churchill Livingstone; 1996.

Bisaglia M, Venezia V, Piccioli P, Stanzione S, Porcile C, Russo C, et al., Acetaminophen protects hippocampal neurons and $\mathrm{PC} 12$ cultures from amyloid beta-peptides induced oxidative stress and reduces NF-kappaB activation. Neurochem. Int. 2002;41(1):43-54.

Blecharz-Klin K, Joniec-Maciejak I, Piechal A, Pyrzanowska J, Wawer A, Widy-Tyszkiewicz E. Paracetamol impairs the profile of amino acids in the rat brain. Environ. Toxicol. Pharmacol. 2014;37(1):95-102.

Cheng A, Hou Y, Mattson MP. Mitochondria and Neuroplasticity. ASN Neuro. 2010 Sep 2;2(5):AN20100019.

Ellman GL, Courtney KD, Andres V, Feather-Stone RM. A new and rapid colorimetric determination of acetylcholinesterase activity. Biochem. Pharmacol. 1961;7:88-95. 
Ferrer I, Gullotta F. Down's syndrome and Alzheimer's disease: dendritic spine counts in the hippocampus. Acta Neuropathol. (Berl.). 1990;79(6):680-5.

Fischer LJ, Green MD, Harman AW. Levels of acetaminophen and its metabolites in mouse tissues after a toxic dose. J. Pharmacol. Exp. Ther. 1981; 219(2):281-6.

Garey LJ, Ong WY, Patel TS, Kanani M, Davis A, Mortimer AM, et al., Reduced dendritic spine density on cerebral cortical pyramidal neurons in schizophrenia. J. Neurol. Neurosurg. Psychiatry. 1998; 65(4): 446-53.

Guo X, Nzerue C. How to prevent, recognize, and treat druginduced nephrotoxicity. Cleve. Clin. J. Med. 2002 Apr;69(4):289-290, 293-294, 296-297 passim.

Halliwell B. Oxidative stress and neurodegeneration: where are we now? J. Neurochem. 2006; 97(6): 1634-58.

Henderson CJ, Wolf CR, Kitteringham N, Powell H, Otto D, Park BK. Increased resistance to acetaminophen hepatotoxicity in mice lacking glutathione S-transferase Pi. Proc. Natl. Acad. Sci. U. S. A. 2000; 97(23):12741-5.

Joshi M, Tyndale RF. Induction and recovery time course of rat brain CYP2E1 after nicotine treatment. Drug Metab. Dispos. Biol. Fate Chem. 2006; 34(4):647-52.

Kaizer RR, Corrêa MC, Spanevello RM, Morsch VM, Mazzanti $\mathrm{CM}$, Gonçalves JF, et al., Acetylcholinesterase activation and enhanced lipid peroxidation after long-term exposure to low levels of aluminum on different mouse brain regions. J. Inorg. Biochem. 2005; 99(9):1865-70.

Khayyat L, Essawy A, Sorour J, Soffar A. Tartrazine induces structural and functional aberrations and genotoxic effects in vivo. Peer J. 2017; 5:e3041.

Lai K-O, Jordan BA, Ma X-M, Srivastava DP, Tolias KF. Molecular Mechanisms of Dendritic Spine Development and Plasticity. Neural Plast. 2016; 1-3.

Manyike PT, Kharasch ED, Kalhorn TF, Slattery JT. Contribution of CYP2E1 and CYP3A to acetaminophen reactive metabolite formation. Clin. Pharmacol. Ther. 2000 Mar;67(3):275-82.

Mohamed M, Mohamed H, Abd El-Hakem A. Effects of Paracetamol and Monosodium Glutamate on Cerebellar Granule Cells of the Adult Male Albino Rats: A Histological and Morphometric Study. Med. J. Cairo Univ. 2014; 82(2):289-302.

Mohammed ET, Safwat GM. Assessment of the ameliorative role of selenium nanoparticles on the oxidative stress of acetaminophen in some tissues of male albino rats. Beni-Suef Univ. J. Basic Appl. Sci. 2013; 2(2): $80-5$.

Nencini C, Giorgi G, Micheli L. Protective effect of silymarin on oxidative stress in rat brain. Phytomedicine Int. J. Phytother. Phytopharm. 2007; 14(2-3):129-35.

Nimchinsky EA, Sabatini BL, Svoboda K. Structure and function of dendritic spines. Annu. Rev. Physiol. 2002; 64: 313-53.
Ojo O, Kabutu F, Bello M, Babayo U. Inhibition of paracetamol-induced oxidative stress in rats by extracts of lemongrass (Cymbropogon citratus) and green tea (Camellia sinensis) in rats. Afr. J. Biotechnol. 2006; 5(12):1227-32.

Posadas I, Santos P, Blanco A, Muñoz-Fernández M, Ceña V. Acetaminophen induces apoptosis in rat cortical neurons. PloS One. 2010; 5(12):e15360.

Purpura DP. Dendritic spine "dysgenesis" and mental retardation. Science. 1974; 186(4169):1126-8.

Sener G, Sehirli AO, Ayanoğlu-Dülger G. Protective effects of melatonin, vitamin $\mathrm{E}$ and $\mathrm{N}$-acetylcysteine against acetaminophen toxicity in mice: a comparative study. J. Pineal Res. 2003;35(1):61-8.

Shankaranarayana Rao BS, Govindaiah null, Laxmi TR, Meti BL, Raju TR. Subicular lesions cause dendritic atrophy in CA1 and CA3 pyramidal neurons of the rat hippocampus. Neuroscience. 2001; 102(2): 319-27.

da Silva MH, da Rosa EJF, de Carvalho NR, Dobrachinski F, da Rocha JBT, Mauriz JL, et al., Acute brain damage induced by acetaminophen in mice: effect of diphenyl diselenide on oxidative stress and mitochondrial dysfunction. Neurotox. Res. 2012; 21(3):334-44.

Takashima S, Ieshima A, Nakamura H, Becker LE. Dendrites, dementia and the Down syndrome. Brain Dev. 1989;11(2):131-3.

Toklu HZ, Sehirli AO, Velioğlu-Oğünç A, Cetinel S, Sener G. Acetaminophen-induced toxicity is prevented by beta-D-glucan treatment in mice. Eur. J. Pharmacol. 2006; 543(1-3):133-40.

Tripathy D, Grammas P. Acetaminophen inhibits neuronal inflammation and protects neurons from oxidative stress. J. Neuroinflammation. 2009; 6:10.

Trumper L, Coux G, Monasterolo LA, Molinas S, García VMC, Elías MM. Effect of acetaminophen on the membrane anchoring of $\mathrm{Na}+$, K+ATPase of rat renal cortical cells. Biochim. Biophys. Acta. 2005; 1740(3):332-9.

Walubo A, Barr S, Abraham AM, Coetsee C. The role of cytochrome-P450 inhibitors in the prevention of hepatotoxicity after paracetamol overdose in rats. Hum. Exp. Toxicol. 2004; 23(1):49-54.

Yousef MI, Omar SAM, El-Guendi MI, Abdelmegid LA. Potential protective effects of quercetin and curcumin on paracetamolinduced histological changes, oxidative stress, impaired liver and kidney functions and haematotoxicity in rat. Food Chem. Toxicol. Int. J. Publ. Br. Ind. Biol. Res. Assoc. 2010; 48(11):3246-61.

\section{How to cite this article:}

Amina E Essawy, Afrah F Alkhuriji, Ahmed A Soffar., Paracetamol Overdose Induces Physiological and Pathological Aberrations in Rat Brain. J App Pharm Sci, 2017; 7 (09): 185-190. 